\title{
Constructing futures; a social constructionist perspective on foresight methodology
}

\author{
Ted Fuller, \\ Teesside Business School, University of Teesside \\ Ted.Fuller@tees.ac.uk \\ Krista Loogma, \\ Institute of Educational Research, Tallinn University \\ loogma@tpu.ee
}

\begin{abstract}
The aim of this paper is to demonstrate the relationship between a particular epistemological perspective and foresight methodology. We draw on a body of social theory concerned with the way that meaning is produced and assimilated by society; specifically, the social construction of knowledge, which is distinguished from its near-neighbour constructivism by its focus on inter-subjectivity. We show that social constructionism, at least in its weak form, seems to be implicit in many epistemological assumptions underlying futures studies. We identify a range of distinctive methodological features in foresight studies, such as time, descriptions of difference, participation and values, and examine these from a social constructionist perspective. It appears that social constructionism is highly resonant with the way in which knowledge of the future is produced and used. A social constructionism perspective enables a methodological reflection on how, with what legitimacy, and to what social good, knowledge is produced. Foresight that produces symbols without inter-subjective meaning neither anticipates, nor produces futures. Our conclusion is that foresight is both a social construction, and a mechanism for social construction. Methodologically, foresight projects should acknowledge the socially constructed nature of their process and outcomes as this will lead to greater rigour and legitimacy.
\end{abstract}

\section{Introduction}

In this article we consider the contribution that social constructionism makes to foresight methodologies. We take the term 'methodology' to mean 'methods of knowing', i.e. an explanation of 'how we know' something. As Andrew Sayer says, a methodology needs to be appropriate to the nature of the object under study and the purpose and expectation of the study. Methodologies are puzzle solving devices and require us to make assumptions of what the world is and what stands for knowledge. [35, p92]. There are many puzzles about the future that we would wish to solve. However, our focus here is on the general features of approaches to understanding and making sense of futures, i.e. knowledge-creating activities that are associated with the term foresight. Our focus is not on how the future is produced, but the grounds we have to make claims about knowledge relating to the future.

A common feature of the way that knowledge about futures is created is the centrality of symbols. Meaning, actions, decisions, investments, conflicts and accords rest on 
the interpretations of futures projected and communicated through symbols: words, texts, images, objects and symbolic actions. Symbols such as trend lines, images, models, equations and of course the ubiquitous scenario are the stock-in-trade of foresight activities. Any foresight methodology, i.e. any attempt to validate the design of knowledge creation, should reflect the way that meaning emerges as thoughts and ideas, discourses and texts, anticipations and decisions, about the future.

The article is not about the symbols and symbolism per se, these are taken for granted. Primarily it is about theories of the ways in which meaning is created, understood and acted upon. Its purpose is to help understand and validate processes of doing foresight, i.e. the processes of generating and negotiating meaning and selecting symbols that accompany meaning. Such meaning and the related constructed symbols constitute collective (social) knowing of the future and are thus inherent in foresight methodology; i.e. in our "method of knowing".

We draw on a body of social theory concerned with the way that meaning is produced and assimilated by society; specifically, the social construction of knowledge. We investigate the power and the limitation that this epistemological position provides for 'methods of knowing' about the future. We start with an explanation of the theory, distinguishing it from its near-neighbour constructivism. We then consider a few well-known contributions for foresight and futures studies from a social constructionism perspective. We show that in some cases, it is an explicit feature, but in most cases it is, in our view, apparent but implicit.

We then turn to foresight methodology specifically. We identify a range of general methodological features of foresight work, without the necessity to adhere to any particular episteme or methodology. This allows us the freedom to investigate the nature of these features when considered from a social constructionist perspective. We do not claim the list of features as being comprehensive, nor is that necessary. In passing we note the features appear to have resonance with some of the methodological issues and concerns expressed by foresight practitioners. Finally we reflect on the significance of a social constructionist perspective towards foresight methodologies and ask what are the foundations that foresight is built upon. Our conclusion is that foresight is both a social construction, and a mechanism for social construction. Methodologically foresight projects should acknowledge the socially constructed nature of the process and outcomes as this will lead to greater rigour and legitimacy.

\section{Social construction}

The central idea of social construction is that whenever we employ words or other symbols to refer to objects in our social world, we are constructing them, quite literally, as meaningful social objects that we can take account of in our actions [12, p. 54]. There are several forms of constructivism/constructionism and the "common thread between all forms of constructivism is that they do not focus on an ontological reality, but instead on the constructed reality.” [43].

Constructivism is part of wider framework of symbolic interaction theory $[5,17,30]$, which is related to the sociology of action. Symbolic interactionism is the theory that explanations of order and change come from the observations of everyday life and the interactions between people, rather than from large scale social forces and natural 
laws (Cf. structural functionalism). The approach aimed to uncover processes of communication and interaction that allowed people to make sense of their social world and for them to create or construct the structures that structural functionalists treated simply as social facts [12, p57]. Mead argued that individuals give meaning to the world by defining and interpreting it in certain ways [12, p53]. The premise is that the world is never experienced directly, but through the ideas that we hold about it, and that these are communicated through symbols. Such symbols are not representative of reality in the sense of direct correspondence; their meaning constitutes interpreted reality. As Mead [30, p78] wrote "Symbolization constitutes objects not constituted before, objects which would not exist except for the context of social relationships wherein symbolization occurs”.

The concept of construction in the sociology of knowledge was introduced by Peter Berger and Thomas Luckmann (1967), following Mead, Schutz's sociology of understanding, Garfinkel's ethnomethodology, Durkheims's theory of society, Marxian dialectics, and Weber's constitution of social reality through subjective meaning. In "The Social Construction of Reality: A Treatise in the Sociology of Knowledge” they explored how, rather than having a predisposed nature, humans construct their social world. They argue that any action people undertake is shaped by the different types of knowledge; not only scientific knowledge but cultural and experiential knowledge including "common sense" and the knowledge people use in there everyday activities (Berger and Luckmann, 1967). Their thesis is that "reality" and "knowledge" pertain to specific social contexts, and relations between them have to be included in any analysis of the social phenomena (ibid, p15). It helps us to understand that we actively make and remake social structures and institutions during the course of our everyday activities. Thus knowledge, action and reality, in a pragmatic sense, are not separate from each other and, they claim, can be combined in a comprehensive theory of social action. (p207). Starting out from two noncontradictory statements, "consider social facts as things" [11, p 14]and "both for sociology in the present sense and for history, the object of cognition is the subjective meaning-complex of action” [42, p101], Berger and Luckmann's investigation into "the manner in which reality is constructed" (ibid p.30), marks an important contribution to the sociology of knowledge, which we argue, is crucial in understanding methodological debate in relation to foresight.

There is a range of perspectives and related methodologies that take a constructivist position, a full description of which are outside the scope of this paper. At a broad level, the terms constructivism and constructionism are often used interchangeably. The term constructivism tends to be used when referring to epistemology. Constructivism tends also to be used in relation to individual (psychological) 'constructions of reality', whereas social constructionism asserts that meaning and understandings that emerge from the interactions between people, i.e. neither objectively nor subjectively, but inter-subjectively. A hybrid, 'social constructivism', suggests that the individual constructs his or her world in the head, but with categories supplied by social relationships [14, p 237] Piaget's constructivist theory, e.g. [31,41] is concerned with how learning happens (accommodation and assimilation) and views knowledge as an active construction of the knowing subject, triggered by the cognitive system's need for order and stability. 
An extreme position that reality is 'constructed' is in some cases polarised with notions of essentialism or realism. The essentialist episteme is that forms exist independent of human interpretation or thought and that all things, including human nature, have essential trans-historical characteristics. Radical constructivists e.g von Glasersfeld [15] take the position that since all knowledge is socially constructed it is impossible to know the extent to which knowledge reflects an ontological reality. This does not deny a real world exists, but does deny the possibility that our knowledge of it can be claimed to correspond to it, because human capacity to know it is limited to sensed interpretation.

However, there are many positions between the two polarised theories; they are not always mutually exclusive when considered in the realm of knowledge and knowing and in the performances or actions that result from knowing. There are "weak" constructivist and "strong" constructivist positions. Some hold that certain structural categories exist only because people agree that they exist (e.g. money, citizenship) [32, p202]. Others, such as Sayer, suggest that although ontological reality exists and affects our understanding, our knowledge of it is constructed and fallible.

"Of course knowledge and social phenomena are socially constructed but that doesn't mean external phenomena (including existing material social constructions) cannot influence our interpretations” [35, p91].

The constructivist epistemology and associated theories of knowledge and action are important for foresight. Foresight is intended as a precursor to action and is concerned with the generation of knowledge about the anticipated consequences of different actions, including historical actions. Its authenticity and power relies on the relationship between knowledge and action.

We focus this article on the role of social processes in the construction of meaning because foresight, we argue, is a social process and its purpose is to construct meaning. As a proponent of social constructionism, Gergen [14, p224] argues that a commitment to the objective 'real' seals us off from other possibilities and in eliminating a 'rich sea of alternatives' by quieting alternative discourses, it limits possibilities of action. Social constructionism does not deny reality, it accommodates the human and social power to generate meaningful reality.

\section{Social constructionism in the futures literature}

The very idea of 'knowledge' about an empirically non-existent / 'yet to exist' space implies a dialectic with the empirical real. This could be read as 'subjective' knowledge versus 'objective' knowledge with a distinct sense that subjective knowledge is unscientific, unproven and 'made up', and therefore of little use and/or dangerous to the status quo. Such dualities are deep in western metaphysics, and subject to considerable critique in the context of everyday practice. "Of all the oppositions that artificially divide social science, the most fundamental, and the most ruinous, is the one that is set up between objectivism and subjectivism.” [7, p1] Tapio and Hietanen [38] demonstrate the inter-subjective nature of knowledge that is inherent in a variety of episteme used in futures studies. They suggest that in most implicit futures 'paradigms' knowledge and values (separated in their account) are subjective or inter-subjective. 
A search for the term 'social constructionism' in extant futures literature, yields little result, whether via online databases or in the indexes of key texts. However, constructionism, at least in its weak form, seems to be implicit in much of the epistemological assumptions underlying futures studies. We explore below a range of significant texts to illustrate this point. Three notable contributions to the foresight/futures literature make explicit their methodological relationship to social constructionism; Bell, Slaughter and Inayatullah.

Wendell Bell proposes a critical realist theory of knowledge for futures studies [3, p 236], as a post-positivist and post-Kuhnian epistemology, and therefore more essentialist than relativist. Bell claims that critical realism admits conjectural knowledge. Writing on critical realism and method, Andrew Sayer [34,35] accepts that scientific and social knowledge is socially constructed, i.e. the processes of knowledge creation, acceptance or rejection are social, but this does not deny the existence of causal mechanisms or real external phenomena. This is a 'weak' constructionist position of epistemological relativism, but does not imply ontological relativism [35]. Extant knowledge, though fallible, can provide consistent and reliable models of the world and be shared between people. Similarly one person's interpretation of knowledge does not necessarily stand in equal status to another's. It is interesting that in his chapter on epistemological foundations Bell (with Olick) construct notions of future realist knowledge as posits, surrogate knowledge and presumptively-true (or false) predictions; stating that 'Futurists ... make posits...[and] construct (italics added) surrogate knowledge as reliably and validly as they can" [3, p 238], a process that seems congruent with weak constructionism.

In comparison to Bell, Slaughter takes a much stronger constructionist line in his recent writings. He uses the (reflexive) connection between self-identity and the social construction of knowledge, as a means of elaborating the power of the inner self in society. This is part of the Integral Futures approach, in which Slaughter optimistically casts social constructionism as a force for change for the better. He argues that "social construction moves debates about the currently threatened world and its many futures options away from the simpler and immediate arena of externals to the process of self-understanding, self-constitution and mediation of power and meaning at these formative levels” [37, p110].

The approach is consistent with Inayatullah's work (along with Slaughter and others) in critical futures research. Critical social theory relies on an assumption that language is constitutive of reality, and that the social construction, in language and in everyday practices of a particular event or category, privileges certain interests. The use of deconstruction to detect hidden or implicit meanings embedded in texts, and the interests that such meanings privilege, is an important methodology in critical theory. Causal Layered Analysis (CLA) is a futures oriented form of post-modern deconstruction concerned with "creating distance from current categories" [20, p 816] and problematising such socially constructed categories in order to identify what could or needs to change to produce alternative futures. CLA is an analytical methodology informed by critical social theory. Its links to social constructionism are explicit.

Other foundational work in the Futures Studies literature has strong resonance with social constructionism. Below we indicate how the work in Futures Studies on values 
and vision (Masini) and on conjecture and futuribles, (de Jouvenel) reflect social constructionism.

Values, as part of knowledge that guides human action, are clearly important. Part of the intellectual and social legitimacy of foresight arises from the acceptance of human agency and moral responsibility, which imply an interpretative and reflexive stance with regard to knowledge. Masini $[26,28]$ does not separate values from knowledge in theorising about the way the future is constructed through the power of vision and projects. She argues that absolute values exist at an ontological level, "mediated to the existential level of man in an ongoing process of internalization” (p1166). Such a position implies a realist perspective with regards to values, i.e. moral realism. [4] However, her reference to collective mediation and her reminder that futures thinking is a learning process, suggests a 'weak' constructionist perspective with regards to knowledge implicit in visions.

Masini continues this line of argument by her commitment to the power of vision, (e.g. [28]). Visions have power to produce actions with an intention to change the future, which in turn need to become 'projects' constructed as a base for action. Van de Helm elaborates the theoretical underpinning of vision elsewhere in this edition of Futures [40]. It could be argued that although visions are in some senses 'personal', the construction of what is desirable is more likely to be socially produced. This production arises through languaging and interactions with others and through mimicry of desired social behaviour, whether real or imagined. We suggest that the meaning of 'desirable' is articulated through social interaction and becomes personal vision, need or expectation, rather than personal desires becoming social desires. Thus knowledge of what is desirable is inter-subjectively socially constructed. From this point it could be argued that even the extreme cases of utopian, ideological, or even dystopian, ideals, with their power to transform reality [25] become part of society's articulated desires through the process of social construction.

Two earlier formative ideas of futures include De Jouvenel's [9] 'conjecture' and futuribles can be understood through a social constructionist perspective. De Jouvenel's conjecture is not truth and knowledge i.e. not empiricist/objective, but likelihood or possibility. This perspective on futures studies is interpreted by van de Helm as the transparent construction of conjectures to be exposed to intellectual critique, and not [a] search for the probable. [39, p21]. Masini [27, p22] proposes that conjecture helps us to look at the future on the basis of plausibility as a mental construct; suggesting a strong constructivist perspective, i.e. individual 'visions' are inner models of what is desirable. However, it might be argued when informed by social constructionism, that the power of conjecture is the inter-subjective meaning arising from the construction of the conjecture, through language, and negotiation of its probability. Similarly, we would argue, that futuribles, or reasoned consequences, is a process of social construction - reasoning is a social, rather than a psychological act; reason has no performative power until communicated with others. It is not the conjecture, but the way people act from the conjecture, exercising their own power 'from within' $[9,10]$, that creates futures.

Finally we turn to examples of current work on strategy, technology and foresight. In relation to knowledge and action, a modern practitioner Michel Godet [16] appears to take a constructivist position in stating that creating futures "is above all a state of 
mind (imagination and anticipation) that leads to behaviour (hope and will)" (p8), He describes as a "rebellion against determinism and chance", i.e. implying the power of agency. This is resonant of Azjen's Theory of Planned Behaviour [2], which is concerned with the link between attitudes and behaviour, rather than the construction of knowledge. However, Godet also espouses "thinking unconventionally and collectively" ( $\mathrm{p} 4)$, which is of course a description of a process leading to the social construction of knowledge: unconventionally i.e. non-normatively and collectively, i.e. socially produced.

In the domain of technology, constructionism appears to be increasingly well established, as a report from the 'High Level Expert Group' of the European Commission Research Directorate illustrates.

"The future is there to be made. It is something shaped by people through their purposeful acts and through the unintended consequences of their acts. As such, the future is not there to be 'predicted' but to be socially constructed." [19, p17],

Although this gives social constructionism an instrumental role, rather than seeing it as the way that people produce knowledge, it does reflect an increasing recognition that scientific knowledge is socially constructed[22-24]. Social constructionism has enabled critique of scientific empiricism, leading to a recognition that even in the domains of knowledge that have produced highly verifiable and 'predictable' relationships (theories), the production of knowledge is a social process. A recent example of this in foresight work is Selins' doctoral research on the shaping of nanotechnology. In this case, she focuses on the social constructions of time that are negotiated by heterogeneous actors who have a stake in the future of a particular class of technology, i.e. nanotechnology. Selin [36, p136] concludes that temporal materialities of nanotechnology will "continue to be reconfigured, renegotiated, recoded, and hence re-temporalized”, by the actors engaged in producing its futures.

\section{Foresight methodology from a social constructionist perspective}

If we are able to detect social constructionism in extant methodologies relating to foresight or futures studies, is it possible to synthesise this critical analysis into a more normative perspective? In the everyday practices of undertaking futures-oriented studies, how should a constructionist perspective shape methodology? In order to address this question, we give examples of methodological characteristics that are consistent with investigating futures (whether called futures studies, foresight or forecasting). We are not suggesting that all foresight or futures studies methodologies contain all of these characteristics, but we suggest that when taken together they create a distinctive methodological characterisation. We recognise that this particular classification is constructed and open to debate and that many methodological issues are subsumed in this classification. Thus we are able to analyse and discuss ways in which a social constructionist perspective relates to the distinctive methodological features. 
The approach is not intended to atomise a methodology into discrete acts, but rather to give a sense to the overall implications of taking this particular perspective. It is noticeable that much of what is discussed is already known or assumed implicitly and practiced ad hoc. However, there are also many challenges arising from this analysis for what constitutes rigorous foresight practice.

Time (past/present/future). A pre-requisite for futures work is one or more conceptions of future time.

Following the work of Barbara Adam [1], it is clear that time has many meanings beyond 'clock time'. Adam argues that the meaning of time is socially constructed and that such meaning is performative. Futurists are of course used to dealing with short, medium and long-term perspectives, but it has been shown [36] that differences in the construction of time play a significant role in the construction of meaning about the future (e.g. of nanotechnologies). The generic methodological requirement from this perspective is an explicit account of the construction of time within the context of the study at hand.

Descriptive difference: Futures work is concerned largely with changes or differences from the status quo or present. Thus a methodological characteristic of the work is description of change, i.e. real or imagined changes in ontology.. Abstraction from whole worlds and re-categorising of concepts or events are fundamental to producing descriptions of different futures. Such descriptions may be produced by individuals or by groups. They can be articulated in many forms, from an almost unconscious sensing that might accompany personal visioning processes, to a highly explicit representation as story, scenario, movie or cultural dogma.

From a social constructionist perspective the processes of abstraction and classification are not dealing with the real, but with constructions of the real. In particular, social constructionism offers legitimacy for the generation of new conceptual forms of meaning that resonate with empirical observation and/or social discourses. That such conceptions may be challenged with regards to their power relative to alternatives is a legitimate part of the process of knowledge development.

Representation: it is typical of futures work to produce symbolic texts as representations of generated knowledge about futures, often in the form of scenarios and stories, with illustrations.

Strong social constructionism rejects the idea of correspondence between representation and the real. It builds on Saussure's position that the relationship between the linguistic signifier and the object signified is ultimately arbitrary, and thus meaning, as Gergen points out, relies on 'local conventions' [14, p25]. If all knowledge is socially constructed then it is not possible to prove correspondence with the real. What is important is not correspondence but the adequacy of the concept or theory relative to observed world to provide explanation and a predictive capability, if conditional. A weak constructionist perspective, e.g. such as can be found in some forms of critical realism, would argue that although it can never be proven whether representations succeed in exact correspondence, it is possible to move towards correspondence of the real. 
Methodologically, the implication of this perspective is that any implicit or explicit claims that texts and symbols about the future represent or correspond to the future are false. Instead, such representations can be understood as having performative potential, i.e. may change understanding and activity through the way that people interact with and interpret such symbols, and change expectations about the future.

Production of difference. Explaining reasons for described differences involves articulating theories and practice of causality, power and influence, i.e. what produces (or is capable of producing) the difference.

Prediction is not a word espoused in foresight, though 'anticipation' is used to reflect an expectation of being able to identify difference and its production over time. Gergen adds a further insight in a discussion on theory and in particular prediction. He suggests that prediction (such as the theories underlying the engineering of a successful space landing) is created by a community interacting with shared meanings. He says that it is a "mistake to hold that theories (as symbols independent of a community of actors) make predictions"...

"For when the words or symbols of the theory are cut away from a community of users is doesn't tell us anything. [...] There are no consequences. [...] 'Predictions' are effectively moves in meaning, born in relationships. The particular words themselves are simply partial constituents of a social practice we call 'prediction'. [...] The creation of a prediction and its success are community achievements”.

This perspective is profound in the context of foresight. It situates knowledge of the future as epistemically consistent with knowledge of the past and present, in that the future is produced by a community interacting with shared meaning. We would suggest that implicit in this is the position that knowledge generated about the future has a potential to influence the actions of a community which is equal to that of the potential of knowledge of the past or present. Whether such potential is realised depends on its interpretation, resonance and legitimacy by that community.

It is necessary therefore to consider the ways in which knowledge is produced and legitimated by different communities. Rom Harré makes the point clearly when he says:

"Context by context the balance between constructionism and essentialism and between realism and relativism, and how each pair maps on to the other, will be decided in different ways in different contexts.”... "How can [I] be a social constructionist in psychology and a realist in physics?” [18, p xi-xii]

Methodologically, context is important, because dynamical properties of different contexts operate in different ways, for instance, a political party acts differently from a waterfall. Different theories and explanations, even different epistemological assumptions apply to different contexts, as the quotation from Harré (above) exemplifies. If a social constructionist perspective is taken, then such knowledge is considered to be socially produced. The production of domain knowledge is different in different contexts; socio-political knowledge is produced differently from knowledge about the flow of water. This would suggest that in the study of the future 
of a particular domain, the mode by which domain knowledge about the future is produced (i.e. socially constructed) should be explicit, though not necessarily reproduced. One tension that arises if the production mode of knowledge for the domain is reproduced in producing knowledge relating to the future of that domain is that the generation of novel (paradigmic) boundaries and novel structures may be constrained. An example of producing knowledge in a way that acknowledges social constructionism but does not replicate the mode by which it is produced is the use of critical theory by causal layered analysis [20], which acknowledges the hegemony implicit in the production of texts but also deconstructs these.

Simulation: Studies of futures usually involve the generation of alternative worlds (from micro to macro). Examples include alternative scenarios, counter-factual reasoning [6], role-playing and computer based models.

At face value, simulation would appear to be a constructionist, i.e. producing knowledge in the form of models of explicitly non-real worlds. What can these be but constructions? The answer to this depends on the methodology used. One has to ask to what extent does the simulation of the production of knowledge, produce meaning? To what extent is it performative, i.e. produces changes in activity of people?

Let us compare computer based simulation with role-playing as two methods of simulating the production of futures. It is not possible for the simulation of alternative futures within a machine per se to produce social knowledge. However, the social processes leading to the construction of the models used and the interpretation and dissemination of the outcomes of simulation, for instance within a research group can create meaning and produce socially constructed knowledge.

Role play, where humans 'act out' particular events or situations is a social form of simulation. Amongst other things, role playing is used in anticipation of real events (e.g. in disaster planning), in order to prepare participants for the real experiences, as yet unknown, that they may encounter. This would appear to reproduce socially constructed knowledge which, because of the falseness of the situation does not correspond with experiences that will be encountered, but does enable participants, and observers to anticipate what such and event may be like in a real and therefore more uncontrolled environment.

In both of these examples, knowledge is generated, first by modelling possible structures and then by playing out and interpreting what is generated dynamically, i.e. a simulation of events through time, generating (new) meaning from the known through social interaction.

From a social constructionist perspective the model is not a representation but a construction that provides a degree of adequacy in explaining the nature of the phenomena being explored. What is important and salient is the meaning generated by the community that engages with the simulation, and what performative power such engagement has.

Communication of meaning: It is usual for the outcomes of futures work to be communicated to others. One could argue that foresight, as a project, cannot carry social meaning unless its results are communicated to or with others. The texts, 
stories and symbols used to communicate about the future are languaged. Radical constructionists, such at Maturana and Varela [29], consider languaging to be the 'connection' between the individual and the experienced world; it is through languaging that resonance (and hence meaning) is constructed by the individual - that language provides the 'structural capacity' to give meaning to the experienced environment.

As social constructionism places knowledge neither within individual minds nor outside them, but between people, it is the acts of communication and the meaning negotiated in those process that constitute knowledge, not the symbols used. One significant issue arising from this is the degree of responsibility taken or given to foresight as a separate project from its constituency. As a separate project, i.e. acts that 'inform' policy makers or citizens, foresight cannot be responsible for the meaning that emerges amongst its constituency as a result of being informed. If foresight is expected to produce responsible action, then the production of meaning must be embedded in its constituency.

Reflexivity, i.e. reconstructing meaning from a process of interpreted feedback. Wendell Bell suggests that Futures Studies is 'self consciously reflexive' [3, p 237], i.e. the production of descriptions of alternative futures can shape and change everyday understanding and performance.

The concept of reflexivity is consistent with a constructivism, and in particular that our self-identities and social identity are shaped through the interaction with others and the knowledge available to us. Such identities are the result of how people meaningfully regard their actions, and how their identities and interpretations of the external world are constructed and reconstructed from their continuing experiences of that world [13]. This provides what Maturana and Varela called 'structural plasticity', i.e. the power of individual interactions to reshape and create meaning in and of society.

Methodologically, reflexivity is a description of the performative power of social discourse. It suggests that by engaging in reflections of futures, which directly challenge self and community identity, people can produce change. Whether such change is directed outwardly or inwardly depends on the agency and power available. It also suggests how the power of information can work, and furthermore that reflexivity is an ongoing process, producing ever-changing ontologies and discourses, and that any captured articulation of a view of the future is an abstraction of time and space.

Participation. It is common for futures activities, such as foresight programmes, to engage with human actors that have a stake in the future of the specified subject.

A central tenet of social constructionism is that without participation between people in making meaning (or sense-making) no meaning exists. From this perspective participation between people is necessary to generate social knowledge about the future. However, 'participation' in this sense has a wide meaning, for instance it can take place through languaging and discourses. If the results of foresight activities are discourses and actions about the future, then who participates in creating and performing in these discourses has methodological implications. 
In this respect a significant methodological issue is perspectivism, i.e. the conception according to which the world is inhabited by different sorts of subjects or people...which apprehend reality from distinct points of view' [8, p 469]. There are, Gergen suggests, great dangers involved in fixing a particular version of the real and the good [14, p 235]. Participation by people who share a particular perspective is more likely to maintain particular versions of the 'real and the good'.

If the future is created by a diversity of perspectives and the performances arising from these, then any look-ahead to the future should, presumably, acknowledge, synthesise and assimilate the paths that such diversity is in the process of creating. At the very least, foresight methodology should reflect explicitly the perspectives it is taking in 'fixing' the real and the good related to the future.

Thus it is banal to suggest that the inclusion of 'stakeholder groups' in workshops is effecting participation. It may, or it may not. What is important is that the methodology makes explicit the dominant discourses and languages through which participation in the generation of knowledge actually occurs - often done outside such workshop activities. Similarly the extent to which multi perspectives are somehow reduced to a single 'consensus', of a (temporary) fixed future is of methodological significance as is the way that this is achieved. This is not just a political issue though has political consequences - but a question of the degree to which claims to knowledge can be made from single perspectives.

Action: Futures studies and foresight are performative in at least two ways: i) they are concerned with what produces different futures and ii) cognisance of expectations or anticipated future effects of present actions can change or motivate action.

There is a strong rhetorical connection between futures work and actions. Often the explicit purpose of investigating futures is to help choices to be made about what actions are likely to lead to desired futures. Conceptually the radical constructivists Maturana and Varela suggested that "all doing is knowing and all knowing is doing”, and thus do not detach knowing from doing. Methodologically, from a social constructionist perspective, it is the interpretation and construction of meaning from ongoing everyday experiences that produce knowledge and expectations about the future.

Thus action produces futures and also knowledge about futures. Knowledge about futures produces action. Therefore, futures are produced through acts of producing the future in which knowledge is inherent and co-produced by the actors. Separation of action from knowledge reifies one or other. It seems therefore that producing knowledge about futures is part of the act of producing futures. The extent to which some types of act have power lies not in the acts themselves but in their interpretation and meaning, i.e. in their social construction.

Explicit "action research" methods are used in foresight, some tacitly [33], some explicitly: for example "anticipatory action learning" in which the "future is constructed within the terms of the subject" [21, .p658] where metaphors are "not seen as universal but as particular to epistemic communities". Such activities focus 
strongly on the performative qualities of processes that engage communities to attain such visions.

Values: There is a strong normative element in foresight and futures studies, when its purpose is to critique present trajectories, propose better futures, or elaborate expected or desired futures.

A significant criticism of constructionism is that it is inherently relativist, i.e. if knowledge does not correspond with any absolute truth then one account is equally valid as another. For Gergen [14] social constructionism does not carry particular values and has "no position on relativism" (p231). Social constructionism accepts "what is" from an observable empirical perspective, e.g. the existence of poverty, AIDS, $\mathrm{CO}_{2}$ levels etc. The methodological concern is about how such knowledge is produced and how it is legitimised, not the legitimacy (i.e. correspondence) of the knowledge per se.

We would suggest therefore, that adopting a social constructionist perspective in futures work requires a methodology that makes explicit the values that accompany the interpretation of meaning. This requires an exploration of the dominant values of the people or organisations that produce and validate knowledge about the future. This is far from easy to achieve because many values are inherent in the language and concepts used to frame interpretation.

\section{Conclusions: the methodological implications of foresight as a social construction}

Methodological choice depends on the intention or puzzle to be 'solved', and in relation to this, the context. There are many different aims of foresight activities including decision-making, learning, exploration of possibilities, articulation of desirable outcomes, sharing of knowledge, persuasion, encouraging action etc. These aims are set in many different contexts and are concerned with phenomena that behave in many different ways, i.e. have particular ontologies. The commonality is that foresight activities produce knowledge in relation to a future time and such instrumental knowledge is generated by social action, e.g. discourse, language, negotiation.

It appears that social constructionism is highly resonant with the production of foresight knowledge. Central to foresight methodologies is the way in which knowledge is produced and used. Methodologically, the accuracy of the knowledge is less significant than the process by which the knowledge is produced. Gergen says that social constructionism has no position on relativism. However we argue that foresight does have a position on how the salience, accuracy and relevance of knowledge is accepted, rejected, modified and used by society. What is crucial to foresight methodology is an explicit reflection on how, with what legitimacy, and to what social good, knowledge is produced. These issues can be addressed methodologically through the perspective of social constructionism. 
This is not to say that the content of knowledge about the future is irrelevant, but quite the opposite. Relativism can be extremely dangerous in the creation of futures. An understanding of social constructionism is essential for the moral and physical futures of humanity. (Socially constructed) knowledge is fallible, partial, privileged and contestable. The process of social constructionism produces new knowledge, not as a matter of empirical discovery, but as a process of creation.

Knowledge as a creative social process is a powerful explanation for the unpredictability of futures. The future is built on the creation of knowledge and on the way this knowledge guides everyday choices. Work associated with anticipating the unpredictable is constitutive of the future. What is taken as knowledge about the future becomes empirical. The powers that are enacted by and through such knowledge are real. It is essential that such work is methodologically robust.

The analysis in this paper has indicated some of the ways in which social constructionism guides the focus for designing robust foresight methodologies. At an overarching level is the central concept that knowledge, meaning and subsequent actions are produced through the interactions between people. In relation to some of the specific characteristics of foresight methodology, this perspective requires that claims to knowledge should take an explicit account of the:

- Construction of time within the context of the study at hand.

- Power manifest in representational choice

- Performative power of symbolic representations

- Mode by which domain knowledge is produced

- Meaning generated by the community that engages, and what performative power such engagement has

- Degree to which the production of meaning must be embedded in its constituency, in relation to the responsibility taken for subsequent actions

- Performative power of social discourse and challenges to self and community identity

- Dominant discourses and languages through which participation in the generation of knowledge actually occurs

- Interaction between knowledge and action

- Values that accompany the interpretation of meaning

Foresight is both a social construction and a mechanism for social construction. Foresight, as a concept and as practice, is a social construction; there are many examples of how society accepts the value and necessity of anticipating and contemplating futures (e.g. risk assessment, planning, storage and tool-making), so these activities are done. These acts, often institutional, and which are part of everyday life and constitute preparation for the future, are socially constructed. Foresight as a process of contemplating futures is a mechanism for the social construction of knowledge. In the process of enacting foresight programmes and processes, people construct knowledge. Thus most significantly for this article, foresight methodology, the processes and perspective that provide an explanation of 'how we know' something, is a mechanism for the social construction of knowledge. 
The above analysis has demonstrated that far from being a 'new idea' social constructionism has been implicit in the foundations of modern (and post-modern) futures studies. We have shown that this is implicit in the way that more overtly constructivist accounts (visions, hopes and fears, imagination etc) have been assumed to somehow form collective meaning and action and implicit also in the confluence of epistemological and ontological relativism. However, because a constructionist perspective has been implicit, the well grounded foundations of futures studies are open to less than rigorous interpretation. We started this article by considering the place of symbols in the articulation of futures. It is easy to produce symbols of possible futures and in doing so make claims to knowledge about the future.

Foresight methodologies that produce symbols without regard to inter-subjective meaning neither anticipate, nor produce futures. 


\section{References}

[1] B. Adam, Time and Social Theory, Blackwell Publishers in association with Polity Press, Oxford, 1991.

[2] I. Ajzen, The theory of planned behavior.Organizational Behavior and Human Decision Processes 50 (1991) 179.

[3] W. Bell, Foundations of Futures Studies; Human Science for a New Era, Transaction Publishers, New Jersey, 1996.

[4] R. Bhaskar, Dialectic : the pulse of freedom, Verso, London, 1993.

[5] H. Blumer, Symbolic Interactionism: Perspective and Method, University of California Press, Berkeley, 1969.

[6] C. Booth, M. Rowlinson, P. Clark, A. Delahaye, S. Procter, Scenarios and counterfactuals as modal narratives.Futures (forthcoming).

[7] P. Bourdieu, The Logic of Practice, Polity Press, Cambridge, 1990.

[8] E.V. De Castro, Cosmological Deixis and Amerindian Perspectivism.Journal of the Royal Anthropological Institute 4 (1998) 469.

[9] B. de Jouvenel, De pouvoir, Geneva, 1945.

[10] B. de Jouvenel, La Civilisation de la Puissance, Fayard, Paris, 1976.

[11] E. Durkheim, The Rules of Sociological Method, Collier-Macmillan, London, 1950.

[12] J. Fulcher, J. Scott, Sociology, Oxford University Press, Oxford, 2003.

[13] H. Garfinkel, Studies in Ethnomethodology, Prentice Hall., Englewood Cliffs, NJ, 1967.

[14] K. Gergen, An Invitation to Social Construction, Sage, Thousand Oaks and London, 1999.

[15] E.v. Glasersfeld, Radical constructivism : a way of knowing and learning, Falmer, 1996, London, 1995.

[16] M. Godet, Creating Futures; scenario planning as a strategic management tool, Economica, London, 2001.

[17] E. Goffman, The presentation of self in everyday life, University of Edinburgh, Social Sciences Research Centre, Edinburgh,, 1956.

[18] R. Harré, Foreword. in I. Parker (Editor), Social contructionism, discourse and realism, Sage, London, 1998.

[19] High Level Expert Group, in, European Commission Directorate-General for Research Unit RTD-K.2 Brussels, 2002, p. 32.

[20] S. Inayatullah, Causal layered analysis: poststructuralism as method.Futures 30 (1998) 815.

[21] S. Inayatullah, Anticipatory action learning: Theory and practice.Futures 38 (2006) 656.

[22] B. Latour, Science in Action, Open University Press, Milton Keynes, 1987.

[23] B. Latour, S. Woolgar, Laboratory Life: The Social Construction of Scientific Facts, SAGE Publications, Beverly Hills, CA, 1979.

[24] J. Law, J. Hassard (J. Law, J. Hassard(J. Law, J. Hassards), Actor network theory and after, Blackwell/Sociological review, Oxford, 1999.

[25] K. Mannheim, Ideology and Utopia, Routledge, London, 1936. 
[26] E.B. Masini, Rethinking Futures Studies. in Z. Sardar (Editor), Rescuing All Our Futures: The Future of Futures Studies, Adamantine, Twickenham, 1999, p. 36.

[27] E.B. Masini, Futures studies in Italy and The limits to growth.Futures 33 (2001) 21.

[28] E.B. Masini, Rethinking futures studies.Futures 38 (2006) 1158.

[29] H.R. Maturana, F.J. Varela, The Tree of Knowledge, the biological roots of human understanding, Shambhala, London and New York,, 1992.

[30] G.H. Mead, Mind Self and Society from the Standpoint of a Social Behaviorist University of Chicago, Chicago, 1934.

[31] J. Piaget, B. Walsh, Biology and knowledge: an essay on the relations between organic regulations and cognitive processes. (Translated by Beatrix Walsh.), Edinburgh: Edinburgh University Press, 1971.

[32] S. Pinker, The Blank Slate : The Modern Denial of Human Nature, Penguin Books, 2002.

[33] J. Ramos, Dimensions in the confluence of futures studies and action research.Futures 38 (2006) 642.

[34] A. Sayer, Method in Social Science: A Realist Approach., Routledge and Kegan Paul, London, 1992.

[35] A. Sayer, Realism and Social Science, Sage, London, 2000.

[36] C. Selin, Time Matters: Temporal harmony and dissonance in nanotechnology networks.Time Society 15 (2006) 121.

[37] R.A. Slaughter, Futures Beyond Distopia; Creating Social Foresight, RoutledgeFalmer, London, 2004.

[38] P. Tapio, O. Hietenan, Epistemology and public policy: using a new typology to analyse the paradigm shift in Finnish transport futures studies.Futures 34 (2002) 597.

[39] R. Van Der Helm, Towards a clarification of probability, possibility and plausibility: How semantics could help futures practice to improve.Foresight 8 (2006) 17.

[40] R. van der Helm, The Vision Phenomenon; Towards a theoretical underpinning of visions of the future and envisioning.Futures; (forthcoming).

[41] B.J. Wadsworth, Piaget's theory of cognitive and affective development : foundations of constructivism, Longman, White Plains, N.Y., 1996.

[42] M. Weber, The Theory of Social and Economic Organization, Oxford University Press, New York, 1947.

[43] Wikipedia. Constructivist epistemology. Retrieved 11 August 2006 10:55 UTC, from http://en.wikipedia.org/w/index.php?title=Constructivist_epistemology\&oldid $=68990989$ 